\title{
Attention deficit and impulsivity: selecting, shifting, and stopping
}

Citation for published version (APA):

Kenemans, J. L., Bekker, E. M., Lijffijt, M., Overtoom, C. C., Jonkman, L. M., \& Verbaten, M. N. (2005).

Attention deficit and impulsivity: selecting, shifting, and stopping. International Journal of

Psychophysiology, 58(1), 59-70. https://doi.org/10.1016/j.jpsycho.2005.03.009

Document status and date:

Published: 01/01/2005

DOI:

10.1016/j.jpsycho.2005.03.009

Document Version:

Publisher's PDF, also known as Version of record

Document license:

Taverne

Please check the document version of this publication:

- A submitted manuscript is the version of the article upon submission and before peer-review. There can be important differences between the submitted version and the official published version of record.

People interested in the research are advised to contact the author for the final version of the publication, or visit the DOI to the publisher's website.

- The final author version and the galley proof are versions of the publication after peer review.

- The final published version features the final layout of the paper including the volume, issue and page numbers.

Link to publication

\footnotetext{
General rights rights.

- You may freely distribute the URL identifying the publication in the public portal. please follow below link for the End User Agreement:

www.umlib.nl/taverne-license

Take down policy

If you believe that this document breaches copyright please contact us at:

repository@maastrichtuniversity.nl

providing details and we will investigate your claim.
}

Copyright and moral rights for the publications made accessible in the public portal are retained by the authors and/or other copyright owners and it is a condition of accessing publications that users recognise and abide by the legal requirements associated with these

- Users may download and print one copy of any publication from the public portal for the purpose of private study or research.

- You may not further distribute the material or use it for any profit-making activity or commercial gain

If the publication is distributed under the terms of Article $25 \mathrm{fa}$ of the Dutch Copyright Act, indicated by the "Taverne" license above, 


\title{
Attention deficit and impulsivity: Selecting, shifting, and stopping
}

\author{
J.L. Kenemans ${ }^{\text {a,* }}$, E.M. Bekker ${ }^{\text {a }}$, M. Lijffijt ${ }^{\text {a }}$, C.C.E. Overtoom ${ }^{\text {a }}$, L.M. Jonkman ${ }^{\text {b }}$, M.N. Verbaten ${ }^{\text {a }}$ \\ ${ }^{a}$ Department of Psychonomics and Psychopharmacology, Utrecht University, Heidelberglaan 2, 3584 CS Utrecht, The Netherlands \\ ${ }^{\mathrm{b}}$ Department of Neurocognition, Maastricht University, The Netherlands
}

Received 3 August 2004; received in revised form 22 December 2004; accepted 3 February 2005

Available online 13 June 2005

\begin{abstract}
The present selective review addresses attention, inhibition, and their underlying brain mechanisms, especially in relation to attention deficit/hyperactivity disorders (AD/HD), and the effects of methylphenidate. In particular, event-related potential (ERP) studies suggest a deficit in the early-filtering aspect of selective attention in children with $\mathrm{AD} / \mathrm{HD}$. Results from stop tasks are consistent with impairments in stopping performance in $\mathrm{AD} / \mathrm{HD}$, but in children (as opposed to adults) these effects cannot be easily dissociated from more general impairments in attention to the task, and therefore an interpretation in terms of inhibitory control is not straightforward. On the other hand, the beneficial effects of methylphenidate are more specific to stopping, and there are no clearcut effects of methylphenidate on measures of selective attention. Even when group differences pertain specifically to stopping performance (as with adults with AD/HD), ERP evidence suggests at least a partial contribution of differences in switching attention to the stop signal, as revealed in measures of sensory cortex activation. ERP evidence from cued go/nogo tasks underlines the importance of taking into account the contribution of higher order control processes involved in anticipation of and preparation for task stimuli. It suggests that in certain conditions, expectancy, rather than response bias, contributes to increased behavioral response tendencies, and that a presumed index of response inhibition, the nogo N2, may rather reflect conflict monitoring. In sum, direct reflections of brain activity suggest that mechanisms of expectation and attention, rather than of response bias or inhibitory control, govern behavioral manifestations of impulsivity.
\end{abstract}

(C) 2005 Elsevier B.V. All rights reserved.

\section{Introduction}

Attention deficit/Hyperactivity disorder (AD/HD) refers to a cluster of symptoms commonly divided into categories of inattention and hyperactivity/impulsivity. The most prevalent forms are the combined subtype, in which symptoms from both categories are significantly present, and the selective inattentive subtype. In contrast, the selective hyperactivity/impulsivity subtype is relatively rare. Clinical classification in terms of either category or the combined subtype is based on standard diagnostic procedures (interview, questionnaire, etc.). However, it has proven difficult to identify behavioral or biological 'phenotypes' (Castellanos and Tannock, 2002) that covary with the clinical

\footnotetext{
* Corresponding author. Tel.: +31 30 2534907; fax: +31 302537387.

E-mail address: j.1.kenemans@fss.uu.nl (J.L. Kenemans).
}

classification. For example, there are only quantitative, but no qualitative, differences between inattentive and combined subtypes with respect to the measure of background EEG (theta/beta ratio) that primarily differentiates $\mathrm{AD} / \mathrm{HD}$ patients in general from healthy controls (Clarke et al., 2001; there are some qualitative differences in other aspects of the background EEG). Another example is the stop task, which from all laboratory tasks has yielded by far the most robust differences between $\mathrm{AD} / \mathrm{HD}$ patients and controls, at least with respect to its primary parameter, speed of stopping (Oosterlaan et al., 1998; Lijffijt et al., in press-b). Although stopping performance is generally considered pre-eminently suitable to assess impulsivity (Logan et al., 1997), recent studies did not find differences in stopping between groups of inattentive and combined subtypes, respectively (Bedard et al., 2003; Geurts et al., 2004). Moreover, multiple regression analysis recently revealed that stopping perform- 
ance covaried with the total number of $\mathrm{AD} / \mathrm{HD}$ symptoms, rather than specifically with symptoms of impulsivity or inattention (Willcutt et al., in press).

Given that the clinical classification has also no straightforward implications for the choice of treatment, one could wonder about its validity. One possibility is that the clinically assessed balance between inattention and impulsivity/hyperactivity merely reflects random fluctuations in the global behavioral manifestation of a fundamental, relatively homogenous deficit. Another possibility is that the experimental phenotypes that are en vogue, currently or in the past, are simply not sufficiently accurate to dissociate categories of global clinical assessment. With either possibility, it has to be conceded that there is still very limited insight as to what the fundamental deficit(s) is (are) that underlie the various clinical symptoms in AD/HD. Much of the discussion about the nature of the fundamental deficit centers around basic deficits in two putative cognitive functions, attention and inhibition, especially in relation to the combined subtype (Barkley, 1997; Castellanos and Tannock, 2002; Sergeant et al., 2002). At this more fundamental level, attention or selective attention refers to the ability to focus, and maintain that focus, on a limited part of available information, as far as the control of actions is concerned. On the other hand, inhibition or inhibitory control refers to the ability to suppress on-going actions or pre-potent reactions.

In many situations, the relative contributions of attention and inhibition to behavior are hard to disentangle. For example, Stroop word-color interference can be viewed as resulting from insufficient selective attention to the color information, but also from insufficient suppression of the tendency to read the word. AD/HD patients often show abnormal Stroop interference (Homack and Riccio, in press), but it is hard to interpret such findings in terms of either attention or inhibition, without any further information. As will be argued below, even with tasks that seem dedicated to selectively assess inhibition, an interpretation in terms of attention seems perfectly valid as well at second glance. One possible way to break this tie is to resort to measures of brain activity like event-related potentials (ERPs). Although ERP work is also usually presented in the context of themes like 'attention' or 'inhibition,' its very nature allows us to rephrase questions about putative cognitive functions in terms of brain activity, which may provide a more objective basis for identifying mechanisms underlying behavior and behavioral disorders. The present selective review discusses pertinent applications of this strategy, mainly from the authors' recent research.

\section{Selective attention in $\mathrm{AD} / \mathrm{HD}$}

\subsection{Behavioral studies}

Spatial-cuing paradigms are perhaps the best to assess 'pure' selective attention, in that they are specifically about selection of one source of information (in one location) above others. Briefly, target stimuli are preceded by cue stimuli which either validly or invalidly indicate the location of the subsequent target. The difference in speed and accuracy of responding to targets between invalid and valid trials, the validity effect, is assumed to reflect the focusing of attention on the cued location. Results with $\mathrm{AD} / \mathrm{HD}$ children are mixed. Carter et al. (1995) reported a reduced validity effect in children with $\mathrm{AD} / \mathrm{HD}$ : the difference in performance between validly and invalidly cued targets was smaller in patients. Exactly the opposite was found by McDonald et al. (1999), who reported larger validity effects for $\mathrm{AD} / \mathrm{HD}$ children. Interestingly, the patients from the Carter et al. study were described as predominantly inattentive, whereas those from the McDonald et al. study were classified as the combined subtype. Hence, spatialcuing validity effects could function as a phenotype that dissociates clinical subtypes, but this has to be confirmed in integrated studies. For the time being, Huang-Pollock and Nigg (2003), based on a meta-analysis, concluded that there was no indication of a reliable deficit of visual-spatial orienting in $\mathrm{AD} / \mathrm{HD}$, in general or in one of its subtypes.

One study (Nigg et al., 1997) evaluated the effects of methylphenidate on visual-spatial orienting. Their sample of $\mathrm{AD} / \mathrm{HD}$ children did not differ from controls with respect to the validity effect, but showed reduced validity effects under methylphenidate. As such, the effect of methylphenidate resembles that of clonidine, which also has been reported to reduce validity effects (Clark et al., 1988). These seemingly paradoxical effects of a stimulant with agonistic (methylphenidate) and a sedative with primarily antagonistic noradrenergic properties (clonidine, through its agonistic action on autoreceptors) may reflect multiple mechanisms underlying the behavioral outcome in especially the invalidcue condition. Reduced validity effects due to noradrenergic antagonism may reflect reduced focusing of attention on the cued location; those due to methylphenidate may reflect the enhanced ability to switch attention from the invalidly cued location to that of the target. In a similar vein, results for $\mathrm{AD} / \mathrm{HD}$ patients may reflect the balance between impaired focusing (reduced validity effect) and impaired switching (increased validity effect). A somewhat related study reported that in a task-switching paradigm children with $\mathrm{AD} / \mathrm{HD}$ had larger switch costs than control children (Cepeda et al., 2000). Methylphenidate reduces the costs of switching between tasks in $\mathrm{AD} / \mathrm{HD}$ patients (Cepeda et al., 2000; Kramer et al., 2001), which could be consistent with the reduced validity effects under methylphenidate, to the extent that validity effects reflect switching of attention to a new location.

Stroop and related conflict tasks may at least partly yield pure measures of selective attention (in the form of interference scores; see above). Most Stroop studies use traditional varieties in which the colors of incongruent color words have to be named in one condition, and colors of patches or neutral words in another. Homack and Riccio (in 


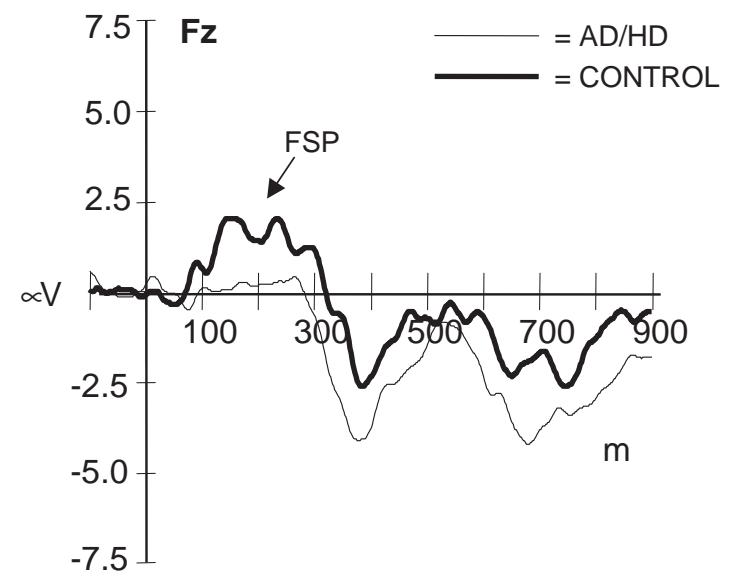

Fig. 1. Difference potentials (relevant or attended minus irrelevant or nonattended, only for non-target stimuli that were not overtly responded to) for $\mathrm{AD} / \mathrm{HD}$ children (thin line) versus a control group (thick line). Part of the difference wave is termed FSP (frontal selection positivity). Adapted from Jonkman et al., 2004.

press) reported on a meta-analysis and concluded that Stroop interference was systematically increased in $\mathrm{AD} /$ HD. Recently, Lansbergen and Kenemans (unpublished data) specifically surveyed Stroop interference results, and concluded that larger interference in $\mathrm{AD} / \mathrm{HD}$ is a robust phenomenon. Larger interference effects have also been reported using other tasks, e.g., those in which interference results from response-incongruent flanker stimuli (Jonkman et al., 1999; Scheres et al., 2003). There are some indications that methylphenidate reduces Stroop interference in AD/HD (De Sonneville et al., 1994), but this was not found for interference from response-incongruent flankers (Jonkman et al., 1999; Scheres et al., 2003).

\subsection{ERP studies}

As discussed, ERPs offer a description of the effect of an experimental manipulation (e.g., 'selective attention') in terms of patterns of brain activity. In principle, this provides a more solid basis for inferring what is going on in the brain than inferences based on behavioral outcomes only. In the context of selective attention, the common methodology is to present participants with streams of stimuli which differ in one or two features. Attention has to be selectively directed only to stimuli with one specific feature (e.g., attend to the blue patterns, ignore all yellows ones; attend to tones in the left, ignore those in the right ear). ERPs are recorded to attended ('relevant') and to ignored ('irrelevant') stimuli, and the difference between these ERPs indexes the effect of the attentional manipulation. Such difference or 'selection' potentials usually take the form of time-varying potential distributions which reflect the sequential selective activation of different cortical areas (e.g., Kenemans et al., 2002a).

Earlier, more or less straightforward applications of this logic to $\mathrm{AD} / \mathrm{HD}$ indicated smaller selection potentials for patients relative to controls (Jonkman et al., 1997; Loiselle et al., 1980; Satterfield et al., 1988, 1990; Van der Stelt et al., 2001; Zambelli et al., 1977; for a review see Barry et al., 2003). Recently, high-resolution spatio-temporal mapping of visual selection potentials in children with $\mathrm{AD} / \mathrm{HD}$ and controls revealed extended abnormalities, even in the earliest phase of attentional modulation (Jonkman et al., 2004). In that study, participants viewed random sequences of red and yellow rectangles. They were instructed to monitor rectangles of only one color for occasionally deviating orientations, and to ignore rectangles of the other color. Fig. 1 shows the main results in terms of selection (difference) potentials. As can be seen, shortly after $100 \mathrm{ms,}$ control children exhibit attentional modulation of stimuluselicited activity, which persists over some hundreds of milliseconds. In contrast, $\mathrm{AD} / \mathrm{HD}$ children completely lack this selective response, up until $200 \mathrm{~ms}$, at which they also show attentional modulation (best seen at other, posterior, electrode sites not shown here).

Fig. 2 shows isopotential maps for two phases of the selection potentials, at $170-\mathrm{ms}$ and $240-\mathrm{ms}$ latencies. At 170 $\mathrm{ms}$, control children exhibit the so-called frontal selection potential (FSP). Dipole source localization for this early effect produced ambiguous results in this sample. Previous research (Kenemans et al., 2002a) in healthy adults suggests that the FSP reflects selective responding in multiple regions of secondary visual cortex, which implements a filter based on a coarse analysis of stimulus features, through which relevant stimuli are selected among irrelevant ones. As
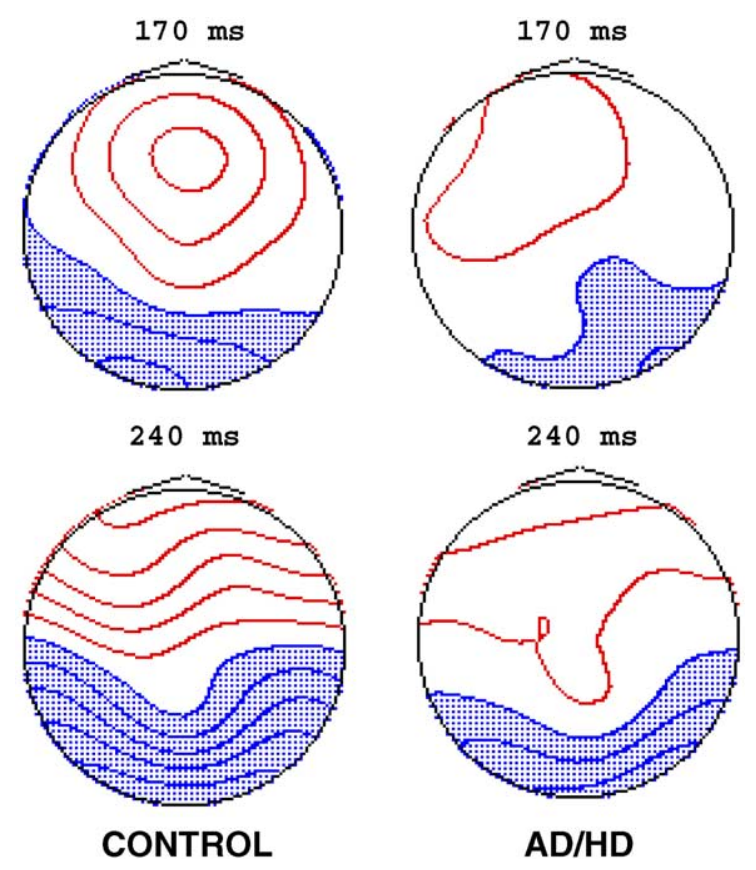

Fig. 2. Isopotential contour maps for two latencies of the difference potentials shown in Fig. 1. Front of the head up, left of the head left. Shading represents negative values, absence of shading positive ones. Spacing is $0.5 \mu \mathrm{V}$. Adapted from Jonkman et al., 2004. 
evident from Figs. 1 and 2, children with AD/HD lack this filtering capacity.

As noted, the $\mathrm{AD} / \mathrm{HD}$ group did exhibit significant selection potentials after $200 \mathrm{~ms}$, but these still differed from the control selection potentials, as revealed in Fig. 2. Dipole source localization did result in unambiguous models for selection potentials at $240 \mathrm{~ms}$, consisting of symmetrical dipole pairs in posterior and anterior regions in both groups (Fig. 3). The anterior dipole pair mainly explains the frontal positivity for this latency in controls (Fig. 2), and was located significantly more anteriorly in $\mathrm{AD} / \mathrm{HD}$ patients. This more anterior location might reflect that the equivalent dipoles are actually located more eccentrically, possibly in (ventral) lateral frontal areas. This in turn might indicate that, in $\mathrm{AD} / \mathrm{HD}$ relative to controls, a smaller stretch of cortical tissue was activated in these areas, which would drive the equivalent dipoles to more eccentric areas. Lateral frontal areas are commonly associated with working memory (e.g., Smith et al., 1998), and these findings might indicate a reduced selective activation of these areas to relevant stimuli in $\mathrm{AD} / \mathrm{HD}$.

Another recent study addressed the auditory counterpart of visual selection potentials like the FSP (Kemner et al., 2004; see also Jonkman et al., 1997). Here, participants had to selectively attend to tones presented to one ear (to detect occasional targets) and ignore those presented in the other ear. Dipole source localization for the resulting auditory selection potential suggested that long-latency $(300 \mathrm{~ms})$ attentional modulation originated from areas very close to the generators of the exogenous N1 and P2 potentials, i.e., in or in the vicinity of (secondary) auditory cortex. This attentional modulation was significantly reduced in the $\mathrm{AD} /$ HD group. At the same time, N1 and P2 did not differ between groups, with regard to either strength or spatial dipole parameters. Under methylphenidate, relative to placebo, the attentional modulation at $300 \mathrm{~ms}$ was enhanced. Dipole analysis again revealed sources in the vicinity of auditory cortex, but at locations significantly different from those found for the control subjects.

In sum, results of behavioral studies are ambiguous with respect to attention deficits in $\mathrm{AD} / \mathrm{HD}$, with respect to whether they really exist, or whether they should be labeled

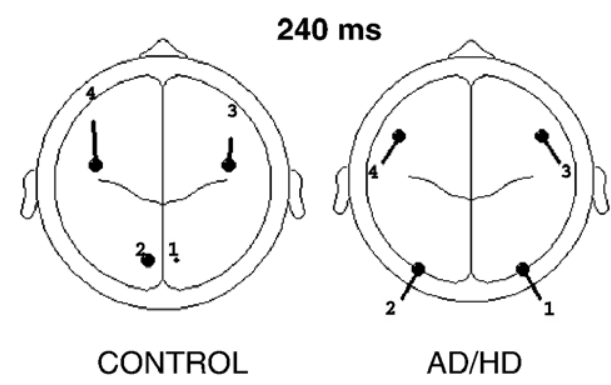

Fig. 3. Equivalent dipole source models for the difference potentials at 240ms latency shown in Figs. 1 and 2. Dots represent the locations of equivalent dipoles, lines the axes of orientation. Adapted from Jonkman et al., 2004 . as attention deficits. ERP studies labeled as addressing selective attention have revealed unambiguous abnormalities in the selective brain response to relevant stimuli, both in secondary visual and auditory cortex, as well as in frontal areas. In behavioral studies, methylphenidate sometimes does, and sometimes does not restore reduced attentional effects that were revealed in comparisons between $\mathrm{AD} / \mathrm{HD}$ children and controls. Consistently, recent ERP work also suggests positive effects of methylphenidate on selective brain responses that, in terms of underlying generators, differ from those found to be abnormal relative to the responses of controls.

A final remark concerns the future direction of attention research in relation to $\mathrm{AD} / \mathrm{HD}$. Recently, cognitive-neuroscientific research on attention has increasingly focused on the issue of attentional control (e.g., Hopf and Mangun, 2000; Kenemans et al., 2002b; Slagter et al., 2005; see also Harter et al., 1989). That is, rather than addressing the effects of attention on behavioral and neurophysiological responses to stimuli (relevant or irrelevant, target or nontarget), research efforts are being centered on the mechanisms that set the brain in response to attentional instructions, before any potential target stimulus has been presented. These endeavors are beginning to reveal a delicate interplay between frontal, parietal, and secondary sensory cortical areas, the exact nature of which depends heavily on the specific attentional instructions (e.g., Corbetta and Shulman, 2002; Slagter et al., 2005). A major factor in deficient attentional selection in $\mathrm{AD} / \mathrm{HD}$ may very well be a deficit of attentional control. Below, an example of this approach in relation to variations in response bias in a continuous-performance task is discussed. Deficits in attentional control may also be easier to relate to structural abnormalities in frontal-cortical, striatal, and cerebellar areas (Durston, 2003).

\section{Inhibitory control in $\mathrm{AD} / \mathrm{HD}$}

\subsection{Behavioral studies}

Studies on inhibitory control have mainly employed continuous-performance tasks (CPTs) and stop tasks. For both paradigms, reliable differences between $\mathrm{AD} / \mathrm{HD}$ and control groups have been claimed based on meta-analyses. With respect to the CPT, differences between $\mathrm{AD} / \mathrm{HD}$ and controls have been reported to be robust for both omission and commission errors (Losier et al., 1996), which would hold across the different varieties of the task (react only to occasional Xs, or to all letters except the occasional X, or to $\mathrm{X}$ only when it is preceded by $\mathrm{A}$ ). Omission and commission errors are generally presumed to index attention and inhibition, respectively. However, ERP work discussed below has revealed that the interpretation of an increase in commission errors in terms of increased impulsivity is not at all straightforward. 
In the stop task participants have to react as quickly as possible to a specific visual stimulus, but have to withhold this response as soon as they perceive a tone. Like the CPT, the stop task assesses measures of attention (mean choice reaction time and within subject standard deviation, SDRT) and inhibition (stop signal reaction time, SSRT), respectively. A recent meta-analysis showed a robust prolongation of SSRT in AD/HD children (Lijffijt et al., in press-b; see also Oosterlaan et al., 1998; see Scheres et al., 2001, for an exception), supporting the inhibition theory that was referred to in the introduction (Barkley, 1997). However, the same meta-analysis also demonstrated that, for children, SSRT effect sizes did not exceed those for mean choice RT and variability of choice RT. These measures at least partly reflect attention to the task stimuli in general. If the difference in SSRT is not different from the difference in $\mathrm{RT}$, then slowed stopping may reflect a deficit of general attention to task stimuli, rather than specifically a deficient inhibitory control.

The same meta-analysis also confirmed the impression from recent studies (Bekker et al., in press-a; Murphy, 2002; Ossmann and Mulligan, 2003) that for adults with $\mathrm{AD} / \mathrm{HD}$ slow stopping is much more specific, as (in the individual studies) there were no group differences in choice reaction parameters. This suggests that stopping is not necessarily dependent on attention, but could reflect a separately operating mechanism, as was originally hypothesized (e.g., Logan, 1994). At first sight, the higher specificity with respect to stopping deficits in adults with $\mathrm{AD} / \mathrm{HD}$ seems to contradict clinical observations of slower decline of inattention in $\mathrm{AD} / \mathrm{HD}$ with age (Biederman et al., 2000). However, it is still possible that this higher specificity holds specifically for combined subtype groups, but that the prevalence of this subtype (relative to the inattentive subtype) is lower in adults. Furthermore, ERP work discussed below suggests that, in addition to attention to task stimuli in general, other aspects of attention may also affect stopping performance, viz., the ability to switch attention from choice reaction to stop stimuli.

Are highly impulsive individuals in the normal population also poor stoppers? This question is important because it speaks to whether $\mathrm{AD} / \mathrm{HD}$ is a qualitatively discernible pathological condition, or whether it is an extreme variety within the continuous distribution of impulsive behavior in pathological and non-pathological populations. Furthermore, samples of non-pathological high-impulsive individuals could serve as model samples for pathological conditions. With respect to stopping, results from studies comparing non-pathological individuals as a function of self-reported impulsivity (Lijffijt et al., 2005) are mixed. Two studies found no difference in stopping performance (Lijffijt et al., 2004; Rodríguez-Fornells et al., 2002), whereas another found poorer stopping performance in high-, relative to low-impulsive individuals (Logan et al., 1997). Lijffijt et al. (2004) found no difference in any stop or choice reaction parameter, except for choice reaction error percentages, which were higher for high-(3.4\%) than for low-impulsive $(2 \%$; not reported in the original article; $t=2.6, p<0.01)$. This result, without concomitant lengthening of choice reaction time could indicate more premature responses, which in turn could imply more impulsive responding in general. Hence, even when stopping performance does not differ between high- and low-impulsive samples from the normal population, high impulsivity may manifest in other task parameters, even when these are traditionally associated more with attention. As will be discussed below, similar results have been found when comparing adults with $\mathrm{AD} / \mathrm{HD}$ and controls.

One variety of the stop task is the change task, in which subject not only withhold their choice reaction response, but actually replace it with yet another response, e.g., a foot response when choice reactions are exerted by hands. Band et al. (2000) reported, for healthy adults, longer SSRTs, but not longer choice RTs in a change, relative to a stop task; in healthy children, however, both were longer for the change task. The finding of longer SSRTs for changing than for stopping is commonly interpreted as reflecting that changing involves a more complex form of selective stopping, which may be based on different brain mechanisms (De Jong et al., 1995). In a group of healthy children (10-13 years of age), Lijffijt (2004) again found longer choice RTs (as well as SSRTs) during changing than during stopping, as well as higher choice error rates. This suggests that the longer RTs do not reflect a cautious response strategy during changing, but rather that the continuous anticipation of having to change every now and then, relative to having to stop, interfered more with choice reaction speed and accuracy. One underlying mechanism for this interference could be that children, on non-change trials, have problems in suppressing the competing tendency for the change response. In a similar vein, Bekker et al. (in press-a) reported, in a group of adults with $\mathrm{AD} / \mathrm{HD}$, a higher rate of false change responses (i.e., change foot responses on nonchange choice reaction trials), relative to controls, as well as a larger variability of correct choice RT. This was interpreted as reflecting an increased overall tendency in the $\mathrm{AD} / \mathrm{HD}$ group to emit change responses on each and every trial, or an increase in the number of choice-response trials in which there was strong competition from the change response. Furthermore, irrespective of task version, choice reaction error rates were higher in the $\mathrm{AD} / \mathrm{HD}$ group, without a concomitant lengthening of choice reaction time. As discussed above in relation to non-pathological impulsivity, such a combined pattern is consistent with a stronger tendency for premature responses, which can be viewed as another manifestation of impulsive responding.

In sum, the stop task and its varieties yield measures, which, at first sight, reflect variation in inhibitory control. However, as group differences in these measures are often hard to dissociate from differences in measures presumably reflecting more general attention to the task (mean and variability of reaction time), putative indices of inhibitory 
control may in fact reflect more general attention. On the other hand, variation in presumed measures of attention (choice error rate, reaction time variability) may on closer inspection reflect differences in impulsive responding. These possibilities should be kept in mind when interpreting group differences in task performance as well as the effects on performance of various treatment manipulations.

In recent years, it has become clear that, in children with $\mathrm{AD} / \mathrm{HD}$, methylphenidate has a robust, dose-dependent improving effect on stopping (SSRT), with doses of close to $1 \mathrm{mg} / \mathrm{kg}$ yielding the largest effects, and doses around 0.5 $\mathrm{mg} / \mathrm{kg}$ yielding intermediate effects, relative to placebo (Bedard et al., 2003; Lijffijt et al., in press-a; Overtoom et al., 2003; Scheres et al., 2003; Tannock et al., 1989, 1995). Also, these effects do not seem to depend on the particular variety of the stop task. Lijffijt et al. (in press-a) addressed the question of specificity in relation to general attention as reflected in choice RT, and found significantly larger improvement for SSRT than for choice RT. Thus, while in AD/HD children impaired stopping may not very specifically reflect impaired inhibitory control, the effect of methylphenidate may more specifically reflect improved inhibitory control. Recent studies in adult AD/HD have revealed a similar pattern of shorter SSRT without changes in choice RT under methylphenidate versus placebo (Aron et al., 2003, using $30 \mathrm{mg}$; Bekker, 2004, using 0.4 and 0.6 $\mathrm{mg} / \mathrm{kg}$ ). As discussed above, specific effects on SSRT may still reflect other attentional factors, such as switching attention to the stop stimulus. As also mentioned above, Kramer et al. (2001) found that methylphenidate enhanced the ability to switch between tasks and focus attention on a new relevant response set.

\subsection{ERP studies using the CPT}

Research looking at ERPs in CPT tasks has mainly been limited to comparisons between ERPs to go stimuli (e.g., occasional X or X after A) and ERPs to nogo stimuli (letters other than X). This contrast commonly yields a larger negativity between 200 and $300 \mathrm{~ms}$ ('N2'), followed by a larger positivity ('frontal P3') over fronto-central areas for nogo, relative to go stimuli, and a larger positivity after 300ms latency over parietal areas ('parietal P3b') for go, relative to nogo stimuli (Bruin et al., 2001; Tekok-Kilic et al., 2001). Generally, the $\mathrm{N} 2$ and the frontal P3 are associated with inhibition (Pfefferbaum et al., 1985; Kok, 1986; Falkenstein et al., 1999), and the parietal P3b is thought to reflect attention to a behaviorally relevant event such as a go stimulus (Picton, 1992).

Overtoom et al. (1998) compared AD/HD children and controls with respect to performance and ERPs in the CPTAX. Control children had larger go P3bs, while there was no difference in nogo N2s. These ERP results mirrored their behavioral findings of larger inattention scores in the $\mathrm{AD} /$ HD group, but no difference in impulsivity scores between groups. Others, however, have reported larger impulsivity scores (more commission errors) as well for $\mathrm{AD} / \mathrm{HD}$ children, relative to controls (Halperin et al., 1992, 1993; Losier et al., 1996).

If $\mathrm{AD} / \mathrm{HD}$ patients respond inadequately to nogo (producing more commission errors) or go stimuli (producing more omission errors), this may very well be related to how they prepare for these stimuli in advance. In the context of the CPT-AX, this refers to the possibility that they differ in the processes of anticipation, preparation, or attentional control, either of which can be assumed to be activated by the A stimulus (the 'cue'), relative to a non-A stimulus ('no cue'). Such preparatory processes are inherently covert in nature, and therefore, they are only accessible on line by using measures additional to performance. In this respect, ERPs are an obvious possibility. In a seminal study, Van Leeuwen et al. (1998) found smaller parietal P3bs and Contingent Negative Variations (CNVs) to cues for $\mathrm{AD} / \mathrm{HD}$ children, relative to controls. Traditionally, the $\mathrm{CNV}$ has been associated with motor or non-motor preparation, and P3b with the amount of information that can be extracted from the eliciting stimulus, information that is used to update memory representations as well as expectations for subsequent events (e.g., Donchin and Coles, 1988). These results suggest that attentional responses, as well as nonspecific or specific motor preparation, that precede a possible target stimulus are reduced in $\mathrm{AD} / \mathrm{HD}$. In turn, this may be a factor in their decreased ability to detect target or go stimuli.

What happens in terms of preparation and inhibition when individuals are tempted to respond impulsively? Bekker et al. (2004) used conditions of varying probability that the cue was indeed followed by a go stimulus. A higher probability resulted in shorter reaction times to go stimuli, as well as a tendency to more commission errors to nogo stimuli. Hence, although this study concerned healthy adults, it could provide a model for impulsive responding and its association with changes in preparatory processes. Fig. 4 presents nogo N2s in two conditions, one in which the probability of a cue being followed by an X (go) was $50 \%$, and one in which it was $75 \%$. N2s were larger in the latter condition, mirroring the increased tendency to produce commission errors. An interpretation in terms of inhibition is that a high go probability results in an increased tendency to respond, which in turn causes greater demands on inhibitory control, which is reflected in a larger N2 (Eimer, 1993). However, the inhibition hypothesis is not consistent with the pattern of responding to the cue that precedes the go or nogo stimuli.

If the inhibition interpretation is valid, then the greater demands on inhibition imply that there is a stronger response tendency or bias that has to be inhibited. In a cued conditional go/nogo task like the CPT-AX, such a stronger response bias should be visible in the interval after the cue, preceding the go or nogo stimuli, as an increase in motor or non-motor preparation reflected in the CNV. Fig. 5 shows cue-elicited $\mathrm{CNVs}$, as protracted negativities starting 
$\mathrm{Fz}$

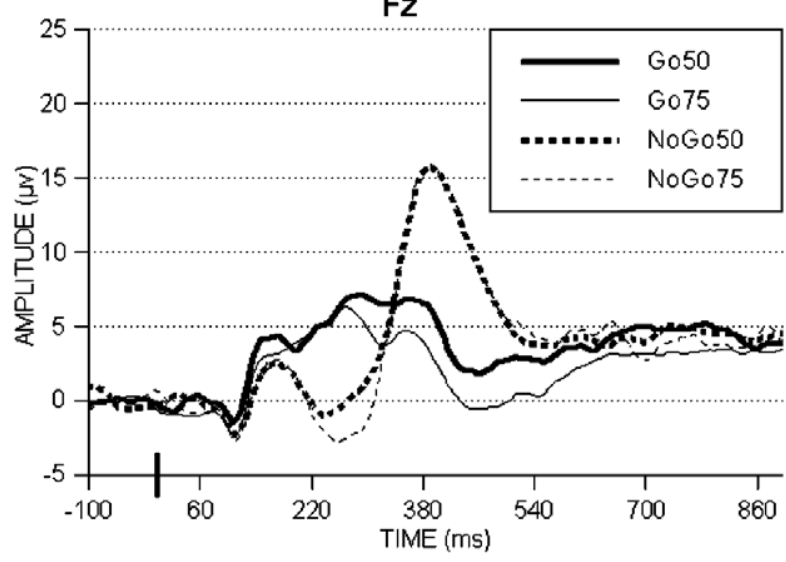

Pz

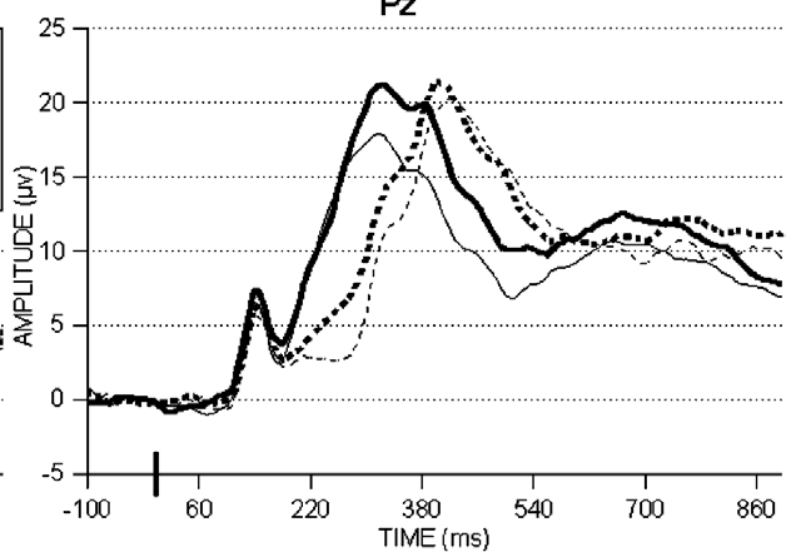

Fig. 4. ERPs to go (X preceded by A) and nogo (non-X preceded by A) stimuli in conditions in which $\mathrm{X}$ followed A with $50 \%$ or with $75 \%$ probability, respectively. Notice larger negativity (N2) for 25\% nogo stimuli between 200- and 300-ms latency (adapted from Bekker et al., 2004).

at about 700-ms latency, for three probability conditions. These were 50,75 , and $100 \%$, and did not differ at all with respect to $\mathrm{CNV}$ amplitude or latency parameters. Fig. 5 also shows that the one difference in cue ERPs between probability conditions concerns a positivity between 300 and 600-ms latency, which is larger with increasing probability. Given this latency, as well as its parietal maximum, this positivity can be reasonably classified as a classical P3b (see above). Rather than by variation in response bias then, variation in target processing was paralleled by variation in a priori expectation for that target. Consistently, in this same data set, the P3b to go stimuli was actually smaller with higher probability (and therefore with higher expectation of $\mathrm{X}$ following an A or B). As such, these results show that, whereas certain behavioral results (i.e., an increase in commission errors) are commonly interpreted as reflecting changes in response bias, electrophysiology paints quite a different picture. This has implications for questions of abnormal impulsive behavior, as when, e.g., $\mathrm{AD} / \mathrm{HD}$ patients show relatively large percentages of commission errors or behavioral response bias.

As discussed above, the increases in nogo N2 amplitude could be interpreted as reflecting higher demands on inhibitory control. This would imply parallel increases in neurophysiological manifestations of motor and non-motor preparation, which was however not confirmed, which in turn argues against the inhibition hypothesis for N2 (the inhibition hypothesis was also disputed by Bruin et al. (2001) albeit on different grounds). An alternative theory is the conflict hypothesis (Nieuwenhuis et al., 2003), which states that the process underlying N2 is activated when a conflict is detected between expected events or dominant response tendencies and the actual event or the actually required response. This theory is not inconsistent with the lack of variation in ERP indices of preparation (Fig. 5), and fits in well with the interpretation of P3b results in terms of variation in expectation. In another study, source localization of the N2 revealed equivalent dipoles consistent with generators in medial-frontal areas, possibly the anterior
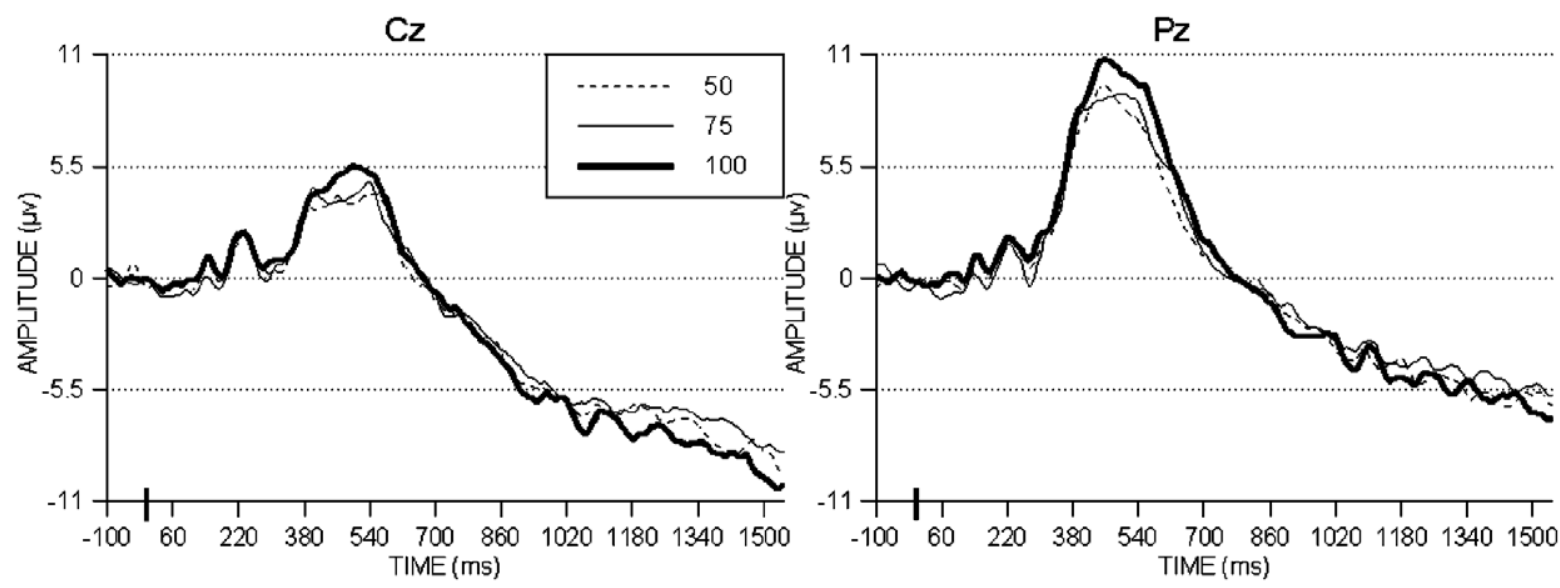

Fig. 5. ERPs to cue stimuli in a continuous-performance task. Cues predicted subsequent go (versus nogo) stimuli with either 50 , 75 , or $100 \%$ certainty (adapted from Bekker et al., 2004). 
cingulate gyrus (Fig. 6; Bekker et al., 2005a; Nieuwenhuis et al., 2003). This is consistent with fMRI studies (Carter et al., 2000; Kerns et al., 2004; Weissman et al., 2003) that revealed specific involvement of anterior cingulate cortex in conflict monitoring or detection.

\subsection{ERP studies using the stop task}

The stop task allows the estimation of the speed of an inherently covert process, i.e., stopping an on-going process. The estimation of this stop signal reaction time (SSRT) involves weighting the choice RT distribution with the proportion of successful stops, and correcting for the stimulus onset asynchrony (SOA) between choice reaction stimulus and stop signal (Logan, 1994). The validity of this estimation however depends on certain assumptions which cannot always be verified, the most notable one being the independence between choice reaction and stop processes. If a difference between SSRTs of two conditions or groups is observed, it could reflect a true difference in stopping performance, but also a difference in the extent to which the assumptions that underlie SSRT estimation are satisfied. Moreover, as argued before, even if there is true difference in stopping performance, the critical underlying factor need not be inhibitory control. ERPs provide a useful measure for correlates of stopping that does not depend on the assumption discussed above, and which reveals brain activity patterns that may yield more insight in the mechanism underlying variation in stopping performance as an outcome measure.

De Jong et al. (1990) were the first to report on the difference in ERPs to stop signals (stop ERPs) between trials on which stopping was successful and those on which stopping failed. Between 150- and 350-ms latency, successful stops were associated with a larger, frontal-centrally distributed, positivity than failed stops were. This 'stop P3'

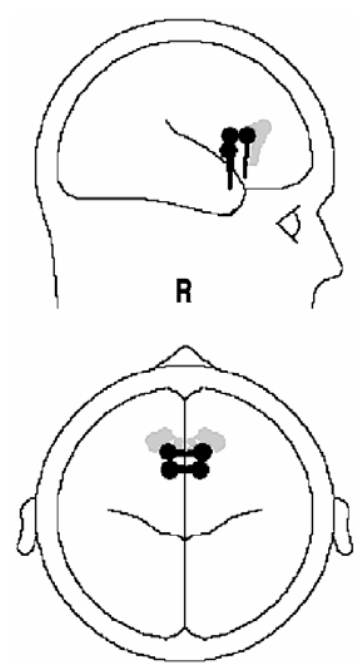

Fig. 6. Equivalent dipole sources for the nogo N2, as estimated from data from two experiments using three conditions and two different estimation procedures (adapted from Bekker et al., 2005a). was also reported by Overtoom et al. (2002) for healthy children (7-12 years of age), that served as controls for an $\mathrm{AD} / \mathrm{HD}$ group. For the latter, the stop P3 was significantly reduced, supporting the conclusion that the longer SSRTs that were observed for this $\mathrm{AD} / \mathrm{HD}$ sample indeed reflected a difference in processing of the stop signals.

The above two studies used visual/auditory varieties of the stop task. Studies employing visual/visual varieties tend to focus more on a negativity ('N2') in the same latency range as the stop $\mathrm{P} 3$, which sometimes is smaller (Dimoska et al., 2003; Van Boxtel et al., 2001), and sometimes is not different (Pliszka et al., 2000) for successful relative to failed stops. The Pliszka et al. (2000) study also concerned a group comparison between children with $\mathrm{AD} / \mathrm{HD}$ and matched controls. Whereas the N2 did not differ between successful and failed stops, it was significantly smaller for the $\mathrm{AD} / \mathrm{HD}$ group than for the controls. To the extent that the N2 is smaller for successful than for failed stops, it can be viewed as reduced positivity for failed stops, consistent with the stop P3 discussed above. It is also possible that it reflects processing of the conflict (Nieuwenhuis et al., 2004; see above) between go and stop stimuli, which may be higher in visual/visual than in visual/auditory versions, because of more perceptual overlap in the former.

A major problem with the stop ERP studies discussed above is the common duration of the stimulus onset asynchronies (SOAs) between choice reaction and stop stimuli. These are in the order of $100-500 \mathrm{~ms}$, which almost ensures that ERPs elicited by the stop stimulus are overlapped and therefore contaminated by ERPs elicited by the choice reaction stimuli. Several attempts at reducing the impact of this overlap have been proposed, among which subtraction from ERPs for successful and failed stops, respectively, of ERPs associated with the corresponding parts (slow and fast) of the choice RT distribution (De Jong et al., 1990), or extensive jittering of the choice-stop SOA (Pliszka et al., 2000), or both (Kok et al., 2004). However, neither of these methods ensures sufficient removal of overlapping choice RT responses, which may cause artificial differences between successful and failed stops, or between groups, with respect to the stop signal ERP. These artifacts may be related to motor potentials present for failed but not for successful stops, or any other difference in processing of the choice reaction stimulus that is systematically associated with the probability of successful stopping, or that is different between groups that are compared with respect to stop ERPs.

Recently, Bekker et al. (2005b) applied the perhaps only available published method that can be expected to deal with the overlap problem to an acceptable extent: the Adjar (Level 2) method as proposed by Woldorff (1993). Using this method in a sample of college students, the larger positivity for successful than for failed stops (stop P3) was confirmed, as shown in Fig. 7. A new additional finding was that successful, relative to failed stops, were associated with an enhanced N1 peak at about 100-ms latency (Fig. 7). The 


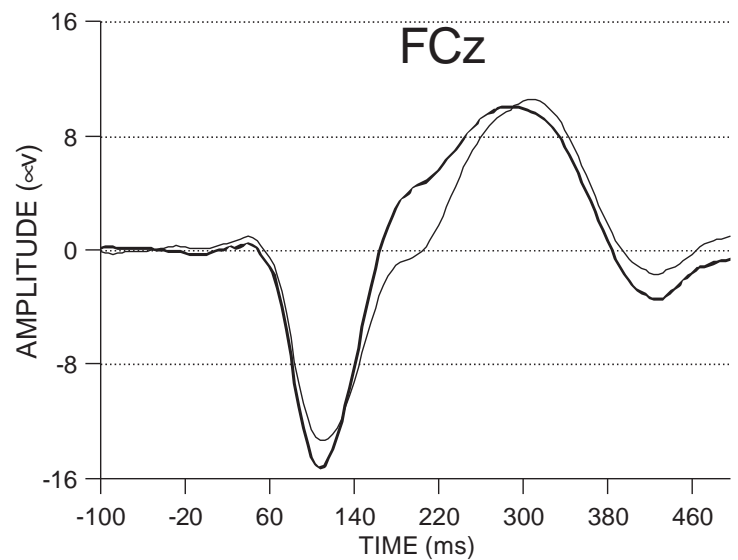

Fig. 7. ERPs to auditory stop signals at a frontal-central electrode site, for successful (thick trace) and failed (thin trace) stops. Overlap from ERPs to preceding choice reaction stimuli was removed using Adjar, Level 2 (Woldorff, 1993) (adapted from Bekker et al., 2005b).

N1 reflects the amount of activation elicited by a stimulus in auditory cortex, and has been shown to be very sensitive to manipulations of attention to that stimulus (e.g., Woldorff and Hillyard, 1991). This raises the intriguing possibility that whether an auditory stop signal results in a successful or a failed stop at least partly depends on the impact the stop
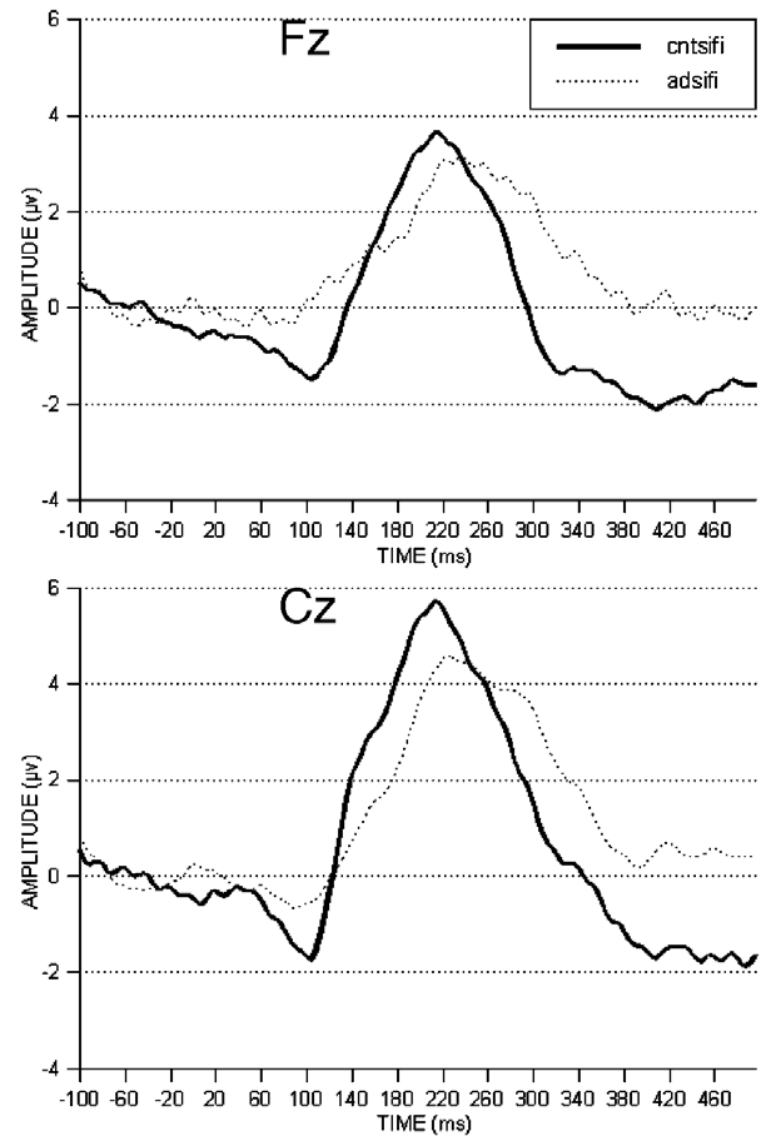

signal has in auditory cortex. The latter, in turn, may be affected by spontaneously fluctuating or more tonic variations in the amount of attention that is paid, or switched, to the stop signal.

Given that successful stops have specific brain-potential correlates at different levels of cortical processing (N1, stop P3), how do these look in poor stoppers? Bekker et al. (in press-b) applied Adjar (Level 2) to a comparison between adults with $\mathrm{AD} / \mathrm{HD}$ (combined subtype) and matched controls. As discussed above, the AD/HD group had significantly longer SSRTs, which were dissociated from choice RTs and other putative measures of more general attention. Again, the controls showed a larger N1 for successful than for failed stops; but as can be seen in Fig. 8, this effect was completely absent in the $\mathrm{AD} / \mathrm{HD}$ group, who also had a smaller stop P3. The lack of an N1 effect in the $\mathrm{AD} / \mathrm{HD}$ group suggests that, while behavioral measures indicate otherwise, impairments in stopping are in fact related to abnormal attentional processing of the stop stimulus. More specifically, adults with AD/HD probably also have spontaneous variation in the N1 response, but for reasons unknown their N1 responses are not systematically associated with successful stopping. More generally, general attention to task stimuli (choice RT) may be undisturbed in
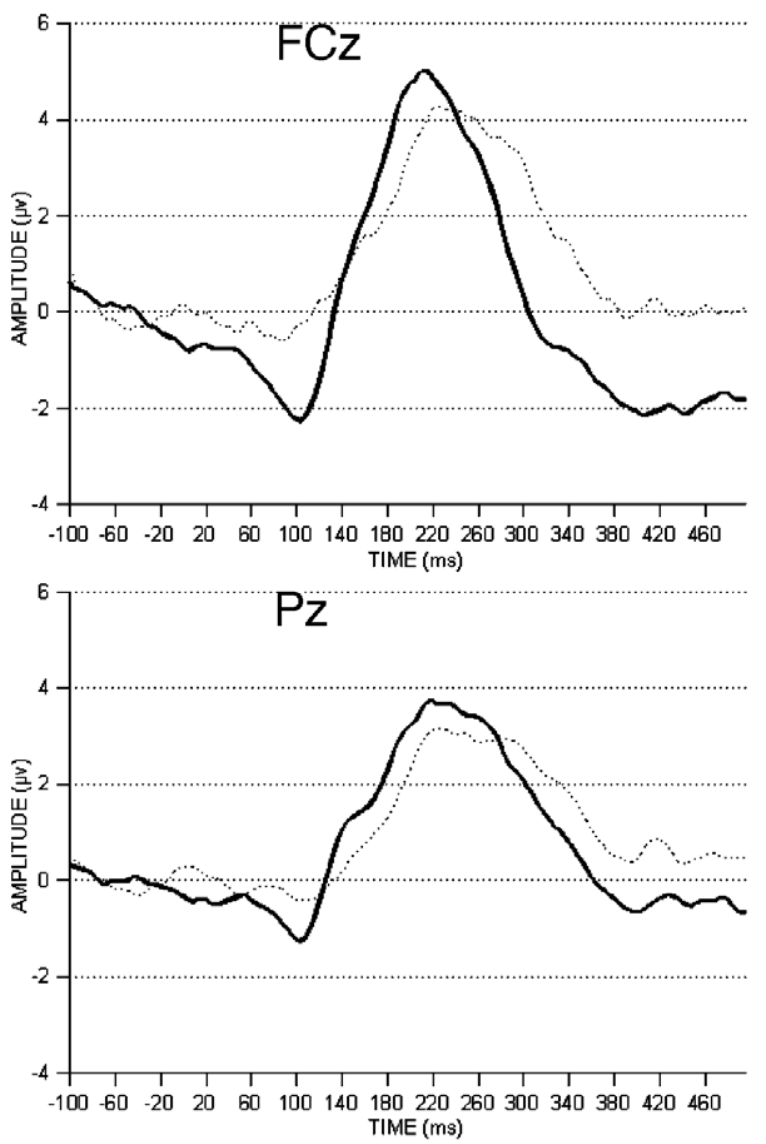

Fig. 8. Difference waves (ERPs to stop signals for successful stops minus those for failed stops) for an adult-AD/HD (dashed trace) and a matched control group (solid trace). Cntsifi-difference wave for controls. Adsifi-difference wave for AD/HD. Adapted from Bekker et al., in press-b. 
adult $\mathrm{AD} / \mathrm{HD}$, but stopping performance may still be impaired by deficiencies in other aspects of attention, e.g., the ability to switch attention to the stop signal.

\section{Conclusion}

Researchers and clinicians dispute whether the primary deficit in $\mathrm{AD} / \mathrm{HD}$ concerns attention, inhibition, or both. A commonly accepted read-out measure for deficient inhibition, i.e., reduced speed of stopping, turned out to be hard to dissociate from reductions in choice reaction speed (which may reflect more general aspects of attention), at least in children. Such a deficiency in (selectively) attending to tasks as a whole is consistent with the systematic reports from $\mathrm{ERP}$ studies that $\mathrm{AD} / \mathrm{HD}$ children have disturbances in the early-filtering aspects of visual and auditory selective attention.

Compared to children, adults with $\mathrm{AD} / \mathrm{HD}$ are characterized by a much more specific reduction in speed of stopping. This conclusion was based on recent individual studies comparing stopping performance general task performance (e.g., Bekker et al., in press-a) in adults with ADHD and controls, as well as on a meta-analytical comparison across adult and child studies (Lijffijt et al., in press-b). However, ERP work suggests that this reduction can at least partly be attributed to abnormalities related to switching of attention to the stop signal. More precisely, the link between the impact of the stop signal in sensory cortex and subsequent stopping performance is weaker than in healthy volunteers. Current research should reveal whether a similar mechanism is involved in deficient stopping in $\mathrm{AD} /$ HD children.

Other paradigms have also yielded alleged measures of inhibition that on closer look are not so straightforward in that respect. In the continuous-performance task (AX version), variation in commission error rate, or transformations thereof, has traditionally been interpreted in terms of variation in inhibitory control. Specifically, the increased commission error rate observed in certain conditions or individuals has been interpreted as reflecting an enhanced commission or response bias. However, ERP substrates of such bias (CNV) do not confirm such an interpretation. Instead, ERP evidence suggests a mechanism of increased expectancy for the presentation of go stimuli underlying the increased commission error rates (when the expectancy is violated), as well as the shorter reaction times to the go stimuli when they are in fact presented (Bekker et al., 2004). Current research should reveal whether and how such control processes contribute to abnormal responses to target and non-target stimuli in certain populations.

Even when inhibition and general attention are hard to dissociate in children with $\mathrm{AD} / \mathrm{HD}$, the beneficial effect of methylphenidate appears to be more pronounced for measures of inhibition. Deficiencies of selective attention are not always remedied by methylphenidate (Jonkman et al., 1999), or only indirectly (Kemner et al., 2004). Further ERP studies should reveal the extent to which improved stopping under methylphenidate, even though it can be dissociated from more general attention, can be attributed to improved switching of attention (cf. Kramer et al., 2001).

More or less the other way around, variation in presumed measures of attention (choice error rate, reaction time variability) may on closer look reflect differences in impulsive responding. Increased choice error rates in $\mathrm{AD} /$ HD patients without concomitant differences in choice reaction times (Bekker et al., in press-a), as well as reduced error rates under methylphenidate in the absence of changes in choice reaction time (Aron et al., 2003; Bekker, 2004), may reflect differences or changes in speed-accuracy trade-offs, which are conceptually more related to impulsivity and inhibition than to attention. Future research efforts should address speed-accuracy trade-offs in patients more explicitly. This may also provide a relevant link to animal literature, in which premature responding is used as a primary read-out measure for impulsivity (e.g., Dalley et al., 2002).

In sum, direct reflections of brain activity suggest that (deficient) mechanisms of expectation and attention, rather than of response bias or inhibitory control, govern behavioral manifestations of impulsivity, and that the apparently specific effect of substances like methylphenidate on inhibitory control may be mediated by effects on expectation and attention.

\section{References}

Aron, A.R., Dowson, J.H., Sahakian, B.J., Robbins, T.W., 2003. Methylphenidate improves response inhibition in adults with attention-deficit/ hyperactivity disorder. Biol. Psychiatry 54, 1465-1468.

Band, G.P.H., van der Molen, M.W., Overtoom, C.C.E., Verbaten, M.N., 2000. The ability to activate and inhibit speeded responses: separate developmental trends. J. Exp. Child Psychol. 75, 263-290.

Barkley, R.A., 1997. ADHD and the Nature of Self-Control. Guilford Press, New York, NY.

Barry, R.J., Johnstone, S.J., Clarke, A.R., 2003. A review of electrophysiology in attention-deficit/hyperactivity disorder: II. Event-related potentials. Clin. Neurophysiol. 114, 184-198.

Bedard, A.-C., Ickowicz, A., Logan, G.D., Hogg-Johnson, S., Schachar, R., Tannock, R., 2003. Selective inhibition in children with attention-deficit hyperactivity disorder off and on stimulant medication. J. Abnorm. Child Psychol. 31, 315-327.

Bekker, E.M., 2004. Inhibitory control and adults with ADHD. Thesis, Utrecht University.

Bekker, E.M., Kenemans, J.L., Verbaten, M.N., 2004. Electrophysiological correlates of attention, inhibition, sensitivity, and bias in a continuous performance task. Clin. Neurophysiol. 115, 2001-2013.

Bekker E.M., Overtoom, C.C.E., Kenemans, J.L., Kooij, J.J., De Noord, I., Buitelaar, J.K., Verbaten, M.N., in press - a. Stopping and changing in adults with AD/HD. Psychol. Med.

Bekker E.M., Overtoom, C.C.E., Kooij, J.J., Buitelaar, J.K., Verbaten, M.N., Kenemans, J.L., in press-b. Disentangling deficits in adults with Attention-Deficit/Hyperactivity Disorder. Arch. Gen. Psychiatry.

Bekker, E.M., Kenemans, J.L., Verbaten, M.N., 2005a. Source analysis of the N2 in a cued go/nogo task. Cogn. Brain Res. 22, $221-231$. 
Bekker, E.M., Kenemans, J.L., Hoeksma, M.R., Talsma, D., Verbaten, M.N., 2005b. The pure electrophysiology of stopping. Int. J. Psychophysiol. 55, 191-198.

Biederman, J., Mick, E., Faraone, S.V., 2000. Age-dependent decline of symptoms of attention deficit hyperactivity disorder: impact of remission definition and symptom type. Am. J. Psychiatry 157, 816-818.

Bruin, K.J., Wijers, A.A., van Staveren, A.S., 2001. Response priming in a go/nogo task: do we have to explain the go/nogo N2 effect in terms of response activation instead of inhibition? Clin. Neurophysiol. 112, $1660-1671$.

Carter, C.S., Krener, P., Chaderjian, M., Northcutt, C., Wolfe, V., 1995. Asymmetrical visual-spatial attentional performance in AD/HD: evidence for a right-hemisphere deficit. Biol. Psychiatry 37, 789-797.

Carter, C.S., MacDonald, A.M., Botvinick, M., Ross, L.L., Stenger, V.A., Noll, D., Cohen, J.D., 2000. Parsing executive processes: strategic vs. evaluative functions of the anterior cingulate cortex. Proc. Natl. Acad Sci. 97, 1944-1948.

Castellanos, F.X., Tannock, R., 2002. Neuroscience of attention-deficit/ hyperactivity disorder: the search for endophenotypes. Nat. Rev., Neurosci. 3, 617-628.

Cepeda, N.J., Cepeda, M.L., Kramer, A.F., 2000. Task switching and attention deficit hyperactivity disorder. J. Abnorm. Child Psychol. 28, $213-226$.

Clark, C.R., Geffen, G.M., Geffen, L.B., 1988. Catecholamines and the covert orientation of attention in humans. Neuropsychologia 27, $131-139$.

Clarke, A.R., Barry, R.J., McCarthy, R., Selkowitz, M., 2001. Electroencephalogram differences in two subtypes of attention-deficit/ hyperactivity disorder. Psychophysiology 38, 212-221.

Corbetta, M., Shulman, G.L., 2002. Control of goal-directed and stimulusdriven attention in the brain. Nat. Rev., Neurosci. 3, 201-215.

Dalley, J.W., Theobals, D.E., Eagle, D.M., Passetti, F., Robbins, T.W., 2002. Deficits in impulse control associated with tonically-elevated serotonergic function in rat prefrontal cortex. Neuropsychopharmacology 26 , $716-728$.

De Jong, R., Coles, M.G., Logan, G.D., Gratton, G., 1990. In search of the point of no return: the control of response processes. J. Exp. Psychol. Hum. Percept. Perform. 16, 164-182.

De Jong, R., Coles, M.G.H., Logan, G.D., 1995. Strategies and mechanisms in nonselective and selective inhibitory motor control. J. Exp. Psychol. Hum. Percept. Perform. 21, 498-511.

De Sonneville, L.M.J., Njiokiktjien, C., Bos, H., 1994. Methylphenidate and information processing. J. Clin. Exp. Neuropsychol. 16, $877-897$.

Dimoska, A., Johnstone, S.J., Barry, R.J., Clarke, A.R., 2003. Inhibitory motor control in children with attention-deficit/hyperactivity disorder: event-related potentials in the stop-signal paradigm. Biol. Psychiatry 54, $1345-1354$

Donchin, E., Coles, M.G.H., 1988. Is the P300 component a manifestation of context updating? Behav. Brain Sci. 11, 357-374.

Durston, S., 2003. A review of the biological bases of $\mathrm{AD} / \mathrm{HD}$ : what have we learned from imaging studies? Ment. Retard. Dev. Disabil. Res. Rev. 9, 184-195.

Eimer, M., 1993. Effects of attention and stimulus probability on ERPs in a go/nogo task. Biol. Psychol. 35, 123-138.

Falkenstein, M., Hoormann, J., Hohnsbein, J., 1999. ERP components in go/nogo tasks and their relation to inhibition. Acta Psychol. 101, 267-291.

Geurts, H.M., Verté, S., Oosterlaan, J., Roeyers, H., Sergeant, J.A., 2004. The many faces of $\mathrm{AD} / \mathrm{HD}$ : executive functioning profiles in $\mathrm{AD} / \mathrm{HD}$ subtypes. Presented at the Third Dutch Endo-Neuro-Psycho Meeting, Doorwerth.

Halperin, J.M., Matier, K., Bedi, G., Sharma, V., Newcorn, J.H., 1992 Specificity of inattention, impulsivity and hyperactivity to the diagnosis of attention deficit hyperactivity disorder. J. Am. Acad. Child Adolesc. Psych. 31, 190-196.
Halperin, J.M., Newcorn, J.H., Matier, K., Sharma, V., McKay, K., Schwartz, S., 1993. Discriminant validity of attention deficit hyperactivity disorder. J. Am. Acad. Child Adolesc. Psych. 32, 1038-1043.

Harter, M.R., Miller, S.L., Price, N.J., LaLonde, M.E., Keyes, A.L., 1989. Neural processes involved in directing attention. J. Cogn. Neurosci. 1, $223-237$.

Homack, S., Riccio, C.A., in press. A meta-analysis of the sensitivity and specificity of the Stroop color and word test with children. Arch. Clin. Neuropsychol.

Hopf, J.M., Mangun, G.R., 2000. Shifting visual attention in space: an electrophysiological analysis using high spatial resolution mapping. Clin. Neurophysiol. 111, 1257-1341.

Huang-Pollock, C.L., Nigg, J.T., 2003. Searching for the attention deficit in attention deficit hyperactivity disorder: the case of visuospatial orienting. Clin. Psychol. Rev. 23, 801-830.

Jonkman, L.M., Kemner, C., Verbaten, M.N., Koelega, H.S., Camfferman, G., v.d. Gaag, R.-J., Buitelaar, J.K., van Engeland, H., 1997. Eventrelated potentials and performance of attention-deficit hyperactivity disorder children and normal controls in auditory and visual selective attention tasks. Biol. Psychiatry 41, 595-611.

Jonkman, L.M., Kemner, C., Verbaten, M.N., Van Engeland, H., Kenemans, J.L., Camfferman, G., Buitelaar, J.K., Koelega, H.S., 1999. Perceptual and response interference in children with attention-deficit hyperactivity disorder and the effects of methylphenidate. Psychophysiology 36, 419-429.

Jonkman, L.M., Kenemans, J.L., Kemner, C., Verbaten, M.N., Van Engeland, H., 2004. Dipole source localization of event-related brain activity indicative of an early visual selective attention deficit in AD/HD children. Clin. Neurophysiol. 115, 1537-1549.

Kemner, C., Jonkman, L.M., Kenemans, J.L., Böcker, K.B.E., Verbaten, M.N., Van Engeland, H., 2004. Sources of auditory selective attention and the effects of MPh in children with AD/HD. Biol. Psychiatry 55, $776-778$.

Kenemans, J.L., Lijffijt, M., Camfferman, G., Verbaten, M.N., 2002a. Splitsecond sequential selective activation in human secondary visual cortex. J. Cogn. Neurosci. 14, 48-61.

Kenemans, J.L., Grent-’t Jong, T., Giesbrecht, B., Weissman, D., Woldorff, M.G., Mangun, G.R., 2002b. A sequence of brain-activity patterns in the control of visual attention. Psychophysiology 39S, 46.

Kerns, J.G., Cohen, J.D., MacDonald, A.W., Cho, R.Y., Stenger, V.A., Carter, C.S., 2004. Anterior cingulate conflict monitoring and adjustments in control. Science 303, 1023-1026.

Kok, A., 1986. Effects of degradation of visual stimulation on components of the event-related potential (ERP) in go/nogo reaction tasks. Biol. Psychol. 23, 21-38.

Kok, A., Ramautar, J.R., De Ruiter, M.B., Band, G.P.H., Ridderinkhof, K.R., 2004. ERP components associated with successful and unsuccessful stopping in a stop-signal task. Psychophysiology 41, 9-20.

Kramer, A.F., Cepeda, N.J., Cepeda, M.L., 2001. Methylphenidate effects on task-switching performance in attention-deficit/hyperactivity disorder. J. Am. Acad. Child Adolesc. Psych. 40, 1277-1284.

Lijffijt, M., 2004. Inhibitory control: ADHD, impulsivity and the influence of psychostimulants. Utrecht University, Dissertation.

Lijffijt, M., Bekker, E.M., Quik, E.H., Bakker, J., Kenemans, J.L., Verbaten, M.N., 2004. Differences between low and high trait impulsivity are not associated with differences in inhibitory control. J. Atten. Disord. 8, 25-32.

Lijffijt, M., Caci, H., Kenemans, J.L., 2005. Validation of the Dutch translation of the 17 questionnaire. Pers. Individ. Differ. 38, $1123-1133$

Lijffijt, M., Kenemans, J.L., Ter Wal, A., Quik, E.H., Kemner, C., Westenberg, H., Verbaten, M.N., Van Engeland H., in press-a. Doserelated effect of methylphenidate on stopping and changing in children with Attention-Deficit/Hyperactivity Disorder. Eur. Psychiatr.

Lijffijt, M., Kenemans, J.L., Verbaten, M.N., Van Engeland H., in press-b. A meta-analytic review of stopping performance in $\mathrm{AD} / \mathrm{HD}$ : deficient inhibitory motor control? J. Abnorm. Psychology. 
Logan, G.D., 1994. On the ability to inhibit thought and action: a users' guide to the stop-signal paradigm. In: Dagenbach, D., Carr, T.H. (Eds.), Inhibitory Processes in Attention, Memory, and Language. Academic Press, San Diego, CA, pp. 189-239.

Logan, G.D., Schachar, R.J., Tannock, R., 1997. Impulsivity and inhibitory control. Psychol. Sci. 8, 60-64.

Loiselle, D., Stamm, J.S., Maitinsky, S., Whipple, S.C., 1980. Evoked potential and behavioral signs of attentive dysfunctions in hyperactive boys. Psychophysiology 17, 193-201.

Losier, B.J., McGrath, P.J., Klein, R.M., 1996. Error patterns on the continuous performance test in non-medicated and medicated samples of children with and without AD/HD: a meta-analytic review. J. Child Psychol. Psychiatry 37, 971-987.

McDonald, S., Bennett, K.M.B., Chambers, H., Castiello, U., 1999. Covert orienting and focusing of attention in children with attention deficit hyperactivity disorder. Neuropsychologia 37, 345-356.

Murphy, P., 2002. Inhibitory control in adults with attention-deficit/ hyperactivity disorder. J. Atten. Disord. 6, 1-4.

Nieuwenhuis, S., Yeung, N., Van den Wildenberg, W., Ridderinkhof, K.R., 2003. Electrophysiological correlates of anterior cingulate function in a go/no-go task: effects of response conflict and trial type frequency. Cogn. Affect. Behav. Neurosci. 3, 17-26.

Nieuwenhuis, S., Yeung, N., Cohen, J.D., 2004. Stimulus modality, perceptual overlap, and the go/no-go N2. Psychophysiology 41, $157-160$.

Nigg, J.T., Swanson, J.M., Hinshaw, S.P., 1997. Covert visual spatial attention in boys with attention deficit hyperactivity disorder: lateral effects, methylphenidate response and results for parents. Neuropsychologia 35, 165-176.

Oosterlaan, J., Logan, G.D., Sergeant, J.A., 1998. Response inhibition in $\mathrm{AD} / \mathrm{HD}, \mathrm{CD}$, comorbid $\mathrm{AD} / \mathrm{HD}+\mathrm{CD}$, anxious, and control children: a meta-analysis of studies with the stop task. J. Child Psychol. Psychiatry $39,411-425$.

Ossmann, J.M., Mulligan, N.W., 2003. Inhibition and attention deficit hyperactivity disorder in adults. Am. J. Psychol. 116, 35-50.

Overtoom, C.C.E., Verbaten, M.N., Kemner, C., Kenemans, J.L., Van Engeland, H., Buitelaar, J.K., Camfferman, G., Koelega, H.S., 1998. Associations between event-related potentials and measures of attention and inhibition in the continuous performance task in children with AD/HD and normal controls. J. Am. Acad. Child Adolesc. Psych. 37, 977-985

Overtoom, C.C.E., Kenemans, J.L., Verbaten, M.N., Kemner, C., van der Molen, M.W., van Engeland, H., Buitelaar, J.K., Koelega, H.S., 2002. Inhibition in children with attention-disorder/hyperactivity disorder: a psychophysiological study of the stop task. Biol. Psychiatry 51, 668-676.

Overtoom, C.C.E., Verbaten, M.N., Kemner, C., Kenemans, J.L., van Engeland, H., Buitelaar, J.K., van der Molen, M.W., van der Gugten, J., Westenberg, H., Maes, R.A.A., Koelega, H.S., 2003. Effects of methylphenidate, desipramine and L-dopa on attention and inhibition in children with attention deficit hyperactivity disorder. Behav. Brain Res. 145, 7-15.

Pfefferbaum, A., Ford, J.M., Weller, B.J., Kopell, B.S., 1985. ERPs to response production and inhibition. Electroencephalogr. Clin. Neurophysiol. 60, 423-434.

Picton, T.W., 1992. The P300 wave of the human event-related potential. J. Clin. Neurophysiol. 9, 456-479.

Pliszka, S.R., Liotti, M., Woldorff, M.G., 2000. Inhibitory control in children with attention-deficit/hyperactivity disorder: event-related potentials identify the processing component and timing of an impaired right-frontal response-inhibition mechanism. Biol. Psychiatry 48, 238-246

Rodríguez-Fornells, A., Lorenzo-Seva, U., Andrés-Pueyo, A., 2002. Are high-impulsives and high risk-taking people more motor disinhibited in the presence of incentive? Pers. Individ. Differ. 32, 661-683.
Satterfield, J.H., Schell, A.M., Nicholas, T.W., Backs, R.W., 1988. Topographic study of auditory event-related potentials in normal boys and boys with attention deficit disorder with hyperactivity. Psychophysiology $25,591-606$.

Satterfield, J.H., Schell, A.M., Nicholas, T.W., Satterfield, B.T., Freese, T.E., 1990. Ontogeny of selective attention effects on event-related potentials in attention-deficit hyperactivity disorder and normal boys. Biol. Psychiatry 28, 879-903.

Scheres, A., Oosterlaan, J., Sergeant, J.A., 2001. Response execution and inhibition in children with $\mathrm{AD} / \mathrm{HD}$ and other disruptive disorders: the role of behavioural activation. J. Child Psychol. Psychiatry 42, 347-357.

Scheres, A., Oosterlaan, J., Swanson, J., Morein-Zamir, S., Meiran, N., Schut, H., Vlasveld, L., Sergeant, J.A., 2003. The effect of methylphenidate on three forms of response inhibition in boys with AD/HD. J. Abnorm. Child Psychol. 31, 105-120.

Sergeant, J.A., Geurts, H., Oosterlaan, J., 2002. How specific is a deficit of executive functioning for attention-deficit/hyperactivity disorder? Behav. Brain Res. 130, 3-28.

Slagter, H.A., Kok, A., Mol, N., Kenemans, J.L., 2005. Spatio-temporal dynamics of top-down control: directing attention to location and/or color as revealed by ERPs and source modeling. Cogn. Brain Res. 22, $333-348$.

Smith, E.E., Jonides, J., Marshuetz, C., Koeppe, R.A., 1998. Components of verbal working memory: evidence from neuro-imaging. Proc. Natl. Acad. Sci. 95, 876-882.

Tannock, R., Schachar, R.J., Carr, R.P., Chajczyk, D., Logan, G.D., 1989. Effects of methylphenidate on inhibitory control in hyperactive children. J. Abnorm. Child Psychol. 17, 473-491.

Tannock, R., Schachar, R., Logan, G., 1995. Methylphenidate and cognitive flexibility: dissociated dose effect in hyperactive children. J. Abnorm. Child Psychol. 23, 235-266.

Tekok-Kilic, A., Shucard, J.L., Shucard, D.W., 2001. Stimulus modality and go/nogo effects on P3 during parallel visual and auditory continuous performance tasks. Psychophysiology 38, 78-589.

Van Boxtel, G.J., van der Molen, M.W., Jennings, J.R., Brunia, C.H., 2001. A psychophysiological analysis of inhibitory motor control in the stopsignal paradigm. Biol. Psychol. 58, 229-262.

Van der Stelt, O., Van der Molen, M., Gunning, W.B., Kok, A., 2001. Neuroelectrical signs of selective attention to color in boys with attention-deficit hyperactivity disorder. Cogn. Brain Res. 12, $245-264$.

Van Leeuwen, T.H., Steinhausen, H.C., Overtoom, C.C., Pascual-Marqui, R.D., Van't Klooster, B., Rothenberger, A., Sergeant, J.A., Brandeis, D., 1998. The continuous performance test revisited with neuroelectric mapping: impaired orienting in children with attention deficits. Behav. Brain Res. 94, 97-110.

Weissman, D.H., Giesbrecht, B., Song, A.W., Mangun, G.R., Woldorff, M.G., 2003. Conflict monitoring in the human anterior cingulate cortex during selective attention to global and local object features. NeuroImage 19, 1361-1368.

Willcutt, E.G., Pennington, B.F., Chhabildas, N.A., Olson, R.K., Hulslander, J.L., in press. Neuropsychological analyses of comorbidity between RD and AD/HD: in search of the common deficit. Dev. Neuropsychol.

Woldorff, M.G., 1993. Distortion of ERP averages due to overlap from temporally adjacent ERPs: analysis and correction. Psychophysiology 30, $98-119$.

Woldorff, M.G., Hillyard, S.A., 1991. Modulation of early auditory processing during selective listening to rapidly presented tones. Electroencephalogr. Clin. Neurophysiol. 79, 170-191.

Zambelli, A.J., Stamm, J.S., Maitinsky, S., Loiselle, D.L., 1977. Auditory evoked potentials and selective attention in formerly hyperactive adolescent boys. Am. J. Psychiatry 134, 742-747. 